\title{
SOCIO-PSYCHOLOGICAL DETERMINANTS OF ADOLESCENT HEALTH AT THE INITIAL STAGE OF PROFESSIONAL EDUCATION
}

DOI: 10.36740/WLek202105119

\author{
Tetiana V. Merkulova ${ }^{1,2}$, Tetiana V. Peresypkina ${ }^{1}$, Ganna M. Cherniakova ${ }^{1,3}$, Valentyna H. Nesterenko ${ }^{4}$, \\ Halyna I. Holubnycha ${ }^{1,3}$, Olha 0 . Holubnycha ${ }^{3}$ \\ 'STATE INSTITUTION «INSTITUTE FOR CHILDREN AND ADOLESCENTS HEALTH CARE AT THE NATIONAL ACADEMY OF MEDICAL SCIENCES OF UKRAINE», \\ KHARKIV, UKRAINE \\ 2PRIVATE INSTITUTION OF HIGHER EDUCATION «KHARKIV INTERNATIONAL MEDICAL UNIVERSITY», KHARKIV, UKRAINE \\ ${ }^{3}$ V. N. KARAZIN KHARKIV NATIONAL UNIVERSITY, KHARKIV, UKRAINE \\ ${ }^{4}$ KHARKIV NATIONAL MEDICAL UNIVERSITY, KHARKIV, UKRAINE
}

\begin{abstract}
The aim: The aim of research was to determine of socio-hygienic and psychophysiological characteristics of adolescents with different levels of professional readiness at the beginning of professional education.

Materials and methods: Among 451 adolescents aged 15-18 who start vocational training were studied vocational readiness, quality of life related to health, social characteristics, self-assessment of individual psychological and physiological characteristics and needs.

Results: Students of vocational schools have a lower $(p<0.05)$ level of readiness to make decisions and plan future professional activities. Medical students had the highest levels of professional readiness. It was found that $(57.5 \pm 4.3) \%$ of the studied adolescents did not have a clearly defined hierarchy of life spheres and terminal values. There are no significant differences in the quality of life related to health among students of different educational institutions. The highest indicators of satisfaction of basic needs were observed among students of vocational schools. The level of professional readiness of adolescents who studied in the pedagogical field had a greater impact on their physical functioning and mental health; among medical students - social and physical functioning, general and psychological health.

Conclusions: The professional orientation of young students has a significant impact on their health-related quality of life and health-promoting behavior. Students whose behavior depends on external circumstances are a risk group for healthy lifestyle disorders, and their health-preserving behavior is more dependent on the positive impact of the educational environment.
\end{abstract}

KEY WORDS: adolescents, professional readiness, quality of life, health-preserving behavior, psycho-physiological features

Wiad Lek. 2021;74(5):1147-1151

\section{INTRODUCTION}

As a result of the demographic crisis in Ukraine today there is a reduction in the labor potential of society. Under these conditions, the most urgent task is to preserve the health of the younger generation as part of the working population. In the future, this will provide economic and social efficiency, preserve the labor potential of society. Vocational guidance is an integral part of this process $[1,2]$.

Every young man or woman has the right to make a conscious choice of profession. But the vast majority of adolescents choose a profession based only on socio-economic needs. They are often unaware of the specific conditions and nature of professional activities, do not take into account the possible impact of adverse occupational factors on their health, do not take into account their own psycho-physiological characteristics and the adaptive potential of their health [3].

Modern professions due to the use of new technologies, flexible and dynamic forms of production, make specific, strict requirements for the employee's personality. Such requirements presuppose a high level of knowledge and development of certain psychophysiological qualities, opportunities, initiative and independence in work.

According to various data, the professional self-determination of both adolescents graduating from secondary education and those who have already started vocational training has different degrees of expression depending on the psychological and physiological characteristics. Due to the lack of professional knowledge, immaturity of skills and abilities, the initial professional adaptation is due to the mobilization of functional reserves of the body and the stress of psychophysiological functions $[2,4]$. What physiological cost of the adaptation process depends on the functionality of the body systems of adolescents and the formation of motivation in choosing a professional direction. Therefore, the identification of patterns of psycho-physiological state of the body of a teenager studying in a particular specialty is a necessary condition for effective professional adaptation to existing conditions of learning and production activities. 
The formation of high school students' readiness to choose a profession is a dynamic process that includes the acquisition of knowledge, skills and abilities in the future professional sphere, active testing of forces and involvement in cognitive work. It involves the definition and correct assessment of the inclinations and abilities of students and ends with a conscious choice on this basis of the future profession [5]

Under the psychological readiness of high school students to make a conscious choice of future educational profile and profession (professional readiness) is understood as an integrative personal education, which includes professional orientation, professionally important qualities, knowledge and skills and consists of motivational, orientational, emotional, personal and operational, evaluative and reflective components. The value orientations of the individual are one of the most important factors motivating human behavior and underlie its social actions. The content and level of development of personal values determine the degree of socialization and the degree of entry of the individual into the system of social structures and institutions [6].

\section{THE AIM}

The aim of research was to determine of socio-hygienic and psychophysiological characteristics of adolescents with different levels of professional readiness at the beginning of vocational education.

\section{MATERIALS AND METHODS}

The main method of collecting socio-psychological information was the survey method in the form of standardized (formalized) interviews. The study involved adolescents aged 15-18 who was started professional education - 101 students of vocational schools and 350 first-year students of higher educational institutions of various profiles (pedagogical, medical) in Melitopol and Kharkiv.

Professional readiness was studied with the help of a questionnaire (adapted by AP Chernyavska edited by NV Afanasyeva, 2007), which consisted of 99 questions with a dichotomous form of answer, which were distributed in the method at random. The questionnaire consisted of five scales: "autonomy", "awareness", "time orientation" (planning), "decision making", "emotional attitude".

Health-related quality of life was studied using the SF36 methodology, which consists of 36 questions grouped into eight scales: physical functioning, role activity, physical pain, general health, vitality, social functioning, emotional state, and mental health. They form two blocks - the psychological and physical components of health.

Adolescents were also interviewed on gender, age and social characteristics, self-assessment of individual psychological and physiological characteristics and needs. For this purpose, a specially developed questionnaire approved by the Academic Council of SI «ICAHC NAMS» was used.

For processing of the received data packages of the licensed computer application programs "SPSS-17" and "Microsoft" Excel'2007" were used. Materials of researches were processed with use of parametric (dispersion, factor, regression and correlation) and nonparametric ( $\chi 2)$ analysis methods.

The study was conducted taking into account the main provisions and in accordance with the ethical and moral requirements of the Status of the Ukrainian Association for Bioethics and Norms GSR (1992), GLR (2002), the principles of the Helsinki Declaration of Human Rights, the Council of Europe Convention on Human Rights and Biomedicine. medical ethics of the State Institution «Institute for Children and Adolescents Health Care at the National Academy of Medical Sciences of Ukraine». Informed parental consent was obtained prior to the start of the research procedures.

\section{RESULTS}

The professional readiness of students depends on the stage of their education. Students of vocational schools have a lower $(p<0.05)$ level of readiness to make decisions and plan future professional activities. Medical students had the highest levels of professional readiness, primarily in such components as autonomy and willingness to make decisions about their professional future, a responsible attitude to obtaining a profession (fig. 1).

The study of the features of the motivational and value sphere showed that $(57.5 \pm 4.3) \%$ of the studied adolescents did not have a clearly defined hierarchy of life spheres and terminal values. Only $(15.7 \pm 3.1) \%$ of high school students were clearly identified areas of life and values that are most preferred. Among the spheres of life, schoolchildren gave the greatest preference to the sphere of education (34.1 \pm $2.7) \%$ of those who made a clear choice, and among the terminal values - the achievement and preservation of their own individuality $(43.2 \pm 7.5) \%$ and $(40.9 \pm 7.4) \%$, respectively).

For girls, the most important were the value of preserving their own individuality $(17.3 \pm 4.4) \%$ and the sphere of education $(13.3 \pm 3.9) \%$ of the subjects. For boys, the most important value of their own achievements $(20.33 \pm 5.2) \%$ and the sphere of social life $(15.25 \pm 4.7) \%$.

The study of quality of life related to health did not show significant differences among students of higher education institutions of different profiles. Students are least satisfied with their emotional role functioning and mental health, the best indicators of physical and social functioning. At that time, the highest indicators of satisfaction of basic needs were observed among students of vocational schools, which is most likely due to the lack of a holistic responsibility for their health and low levels of professional readiness. In general, the greatest impact on the quality of life of students was the emotional color of their perception of the professional future. 


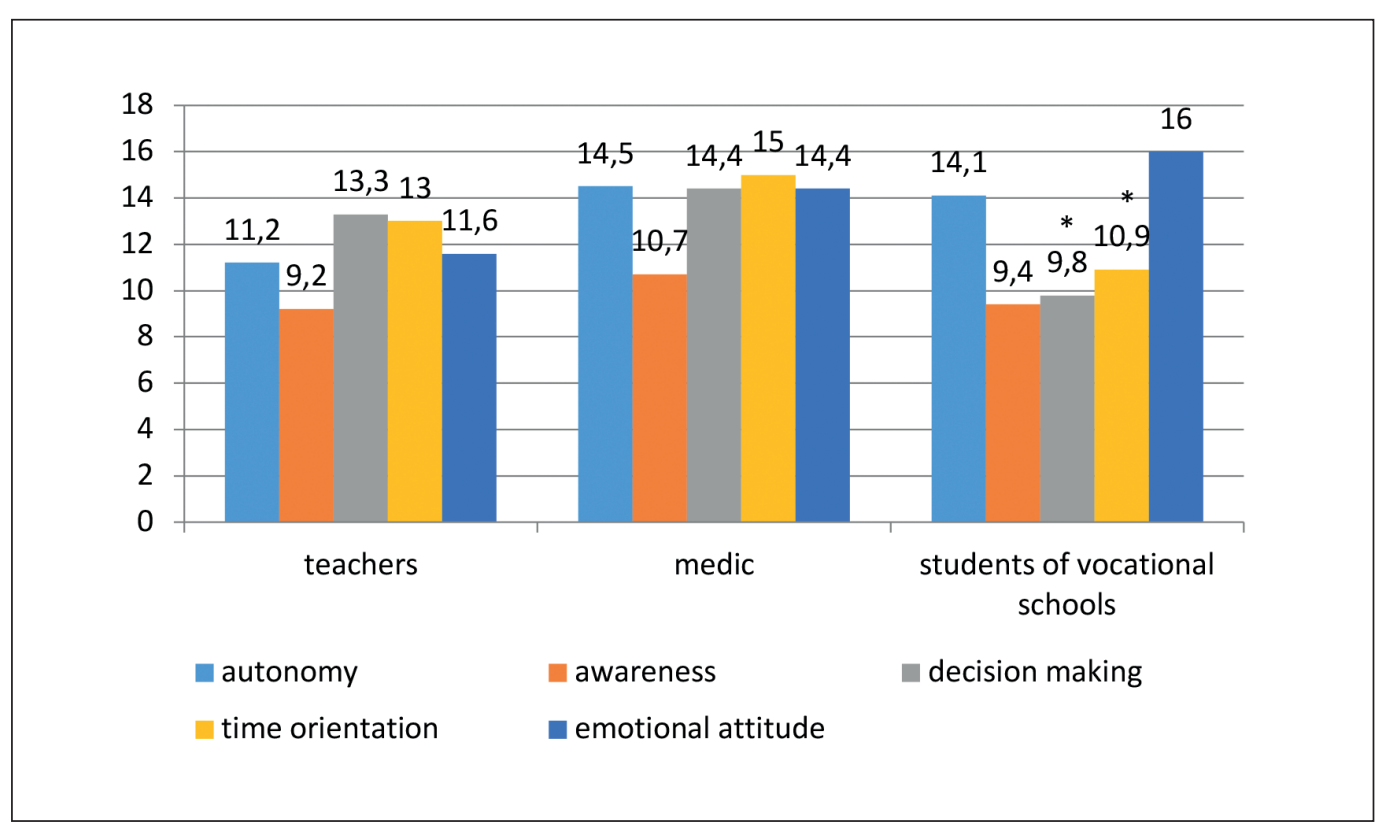

Fig. 1. Levels of professional readiness of adolescents with different learning profiles

Table I. Distribution of students' assessment of their own professional future, $\%$

\begin{tabular}{|c|c|c|c|c|c|c|c|c|c|}
\hline \multirow{3}{*}{ Indicators } & \multicolumn{3}{|c|}{$\begin{array}{c}\text { Students of higher } \\
\text { educational institutions }\end{array}$} & \multicolumn{3}{|c|}{$\begin{array}{c}\text { Students of vocational } \\
\text { schools }\end{array}$} & \multicolumn{3}{|c|}{ Schoolchildren } \\
\hline & ฮू & 商 & 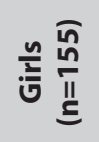 & ฮై & 定命 & ํㅡㄹ & 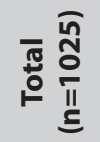 & 高高 & 는 \\
\hline & 1 & 2 & 3 & 1 & 2 & 3 & 1 & 2 & 3 \\
\hline $\begin{array}{c}\text { Depends mainly on external } \\
\text { circumstances }\end{array}$ & 11,2 & 15,2 & $6,5 \#$ & 11,6 & 11,1 & 12,1 & 12,0 & 13,6 & 10,5 \\
\hline $\begin{array}{l}\text { It depends to some extent on } \\
\text { yourself, but more on external } \\
\text { circumstances }\end{array}$ & 18,9 & 19,9 & 8,3 & 23,2 & $27,8 \#$ & 19,0 & 18,3 & 20,7 & 16,0 \\
\hline $\begin{array}{c}\text { Depends equally on yourself and } \\
\text { external circumstances }\end{array}$ & 22,2 & 23,4 & 20,9 & 16,8 & 16,5 & 17,2 & 26,7 & 21,5 & 31,8 \\
\hline $\begin{array}{l}\text { Depends more on yourself than on } \\
\text { external circumstances }\end{array}$ & 18,9 & 14,0 & 24,8 & 15,8 & 11,1 & 19,0 & 19,7 & 19,3 & 20,5 \\
\hline Depends mainly on yourself & 28,7 & 27,5 & 29,4 & $32,8^{*}$ & 33,3 & 32,4 & 23,2 & 24,8 & 21,1 \\
\hline
\end{tabular}

$\#$ - $p$ (boys-girls) $<0,05$

$*-p(1-2-3)<0,05$

Step-by-step regression analysis showed the following. The level of professional readiness of adolescents who studied in the pedagogical field had a greater impact on their physical functioning $(\mathrm{R} 2=6 \%)$ and mental health $(\mathrm{R} 2=10.6 \%)$ mainly in terms of awareness and emotional coloring (formula 1,2 ).

$$
\begin{array}{ll}
\mathrm{PF}=32,1-0,5 \mathrm{X} 2 & \mathrm{R} 2=6 \% \\
\mathrm{MH}=19,5+0,6 \mathrm{X} 5-0,5 \mathrm{X} 1 & \mathrm{R} 2=10,6 \%
\end{array}
$$

Among medical students, such components of professional readiness as the emotional color of choosing a profession, the ability to plan their professional life, the ability to self-determination influenced their social and physical functioning ( $22=24.4 \%$ and $\mathrm{R} 2=7 \%$ respectively), viability $(\mathrm{R} 2=18.4 \%)$, general and psychological health $(\mathrm{R} 2=17.4 \%$ and $\mathrm{R} 2=11.4 \%$, respectively) (formula 3-7).

$\mathrm{PF}=23,2+0,3 \mathrm{X} 1$

$\mathrm{SF}=2,5+0,2 \mathrm{X} 5-0,4 \mathrm{X} 4$

$\mathrm{R} 2=7 \%$

$\mathrm{R} 2=24,4 \%$

$\mathrm{R} 2=18,4 \%$

$\mathrm{R} 2=11,4 \%$

$\mathrm{MH}=14,3+0,4 \mathrm{X} 5$

$\mathrm{R} 2=17,4 \%$

$\mathrm{GH}=10,9+0,3 \mathrm{X} 5+0,2 \mathrm{X} 1$

where $\mathrm{PF}$ - physical functioning;

$\mathrm{RP}$ - role physical functioning;

$\mathrm{RE}$ - role emotional functioning;

$\mathrm{SF}$ - social functioning;

$\mathrm{BP}$ - feeling of pain;

VT - viability;

$\mathrm{MH}$ - mental health; 
$\mathrm{GH}$ - general health

$\mathrm{X} 1$ - autonomy (ability to self-determination)

$\mathrm{X} 2$ - awareness

$\mathrm{X} 3$ - the ability to make decisions

$\mathrm{X} 4$ - the ability to plan your professional life

X 5 - emotional coloring of the choice of profession

A study of the circumstances that affect young people's assessment of their own professional future found that adolescents, whose behavior depends on external circumstances, are at risk for healthy lifestyle disorders, and their health behavior depends more on the positive impact of the educational environment (table I).

The greatest differences between internal and external circumstances of their behavior were observed among students of vocational schools. Thus, they place the pernicious habit of smoking both on external circumstances and exclusively on themselves $(\mathrm{F}=4.6 ; \mathrm{p}=0.01)$. Among university students, the largest group of smokers were those who tend to explain their habit equally by their decisions and external circumstances $(\mathrm{F}=2.5 ; \mathrm{p}=0.04)$. The situation was similar with regard to alcohol consumption. Involvement in sports among student youth mainly depended on the external environment and social environment in which they are.

\section{DISCUSSION}

Despite the availability of a number of studies covering the psychological aspects of vocational guidance of adolescents, there are currently few studies on the physiological, hygienic and medical components of this process. In this regard, this study was relevant.

The research was showed that among all adolescents, regardless of training profile, there were low levels of awareness about the impact on health of factors related to the future profession, the requirements it requires from the body of the worker and the compliance of their own health capabilities with these requirements.

The value orientations of the individual are one of the most important factors motivating human behavior and underlie its social actions. The content and level of development of personal values determine the degree of socialization and the degree of entry of the adolescent into the system of social structures and institutions.

The study of the features of the motivational and value sphere showed the presence of certain gender differences in the individual psychological and physiological characteristics of adolescents. The analysis of the results allowed us to determine the paired relationship between areas and values, which may indicate some of their interaction. Thus, in the field of life, a rather clear connection between the family sphere and the sphere of public life attracted attention, and among the values, the connection between the value of achievements and the preservation of one's own individuality stood out. We can assume that the girls tried to maintain their individuality through education and training, and the boys tried to realize themselves by setting themselves and solving certain problems in the social sphere.

\section{CONCLUSIONS}

At the present stage of education reform in Ukraine provides for the widespread introduction of specialized education in high school. This dictates the need for a radical change in approaches to career guidance of young people, starting from middle school age.

Our research has shown the importance and appropriateness of defining and distributing adolescents by level of professional readiness based on the definition of their autonomy, awareness, the ability to make decisions and plan their own activities, emotional interest in its positive consequences. The professional orientation of young students has a significant impact on their health-related quality of life and health-promoting behavior. It has been determined that students whose behavior depends on external circumstances are a risk group for healthy lifestyle disorders, and their health-preserving behavior is more dependent on the positive impact of the educational environment.

The obtained results can be used in professional testing, distribution of students by abilities to improve adaptation to the educational and production process and in specialized training.

\section{REFERENCES}

1. Kuziv M.Z. Features of vocational guidance in Ukraine. Proceedings of NSU M. Hoholia. 2014;5:162-166.

2. Kochemyrovska 0 . Areas of optimization of state policy in the sphere of development of labor potential of Ukraine. Kyiv: NISD, 2013. http://www.niss.gov.ua/public/File/2013_nauk_an_rozrobku/ trud_potenc.pdf.

3. Danylenko H., Merkulova T., Shvets A., Merkulov V. Preservation of health as the foundation of success of professional self-determination of teenagers. International Journal of Pediatrics Obstetrics and Gynecology. 2017;11(4):8-12.

4. Stelmakhivska V.P., Berzin V.I. Problems of maintaining the health of adolescents while studying in vocational schools. Ukrainian Journal of Clinical and Laboratory Medicine. 2008; 3(2):78-82.

5. Merkulova T. Professional self-determination of young people: modern challenges. Modern problems of hygiene, radiation and environmental medicine. Grodno: GrSMU. 2020;10: 327-336.

The article is the result of the research carried out by research work "Improve medical and psychological support of vocational training of adolescents" (2018 - 2020, № state registration 0118U003185), which was performed within the state order of the State Institution "Institute for Children and Adolescents Health Care at the National Academy of Medical Sciences of Ukraine".

\section{ORCID and contributionship:}

Tetiana V. Merkulova: 0000-0003-2362-9226 ${ }^{A, B, D, F}$

Tetiana V. Peresypkina: 0000-0003-3408-1091 C,D,E,F

Ganna M. Cherniakova: 0000-0002-3960-2485 B,C,D

Valentyna H. Nesterenko: 0000-0002-3773-9525 C,E

Halyna I. Holubnycha: 0000-0001-7832-2091 B,C

Olha O. Holubnycha: 0000-0003-4376-2905 B,E

\section{Conflict of interest:}

The Authors declare no conflict of interest 


\section{CORRESPONDING AUTHOR}

\section{Tetiana V. Merkulova}

State Institution "Institute for Children and Adolescents

Health Care of the National Academy of Medical Sciences of Ukraine"

52-A. Ubileyniy Av, 61153 Kharkiv, Ukraine

tel: +38050738580

e-mail:mvtet@ukr.net

Received: 26.12 .2020

Accepted: 29.03.2021

A - Work concept and design, B - Data collection and analysis, C - Responsibility for statistical analysis,

D-Writing the article, $\mathbf{E}-$ Critical review, $\mathbf{F}$ - Final approval of the article 